\title{
Experimental Study on Effects of Pulverizer Outlet Temperature on Boiler Combustion and Economy
}

\author{
Fuxing Cui, Xuhui Zhang, Haichao Wang
}

State Grid Shandong Electric Power Research Institute, Jinan, 250002, China.

\begin{abstract}
In order to obtain the effects on boiler operation when pulverize outlet temperature changes, testing on a $300 \mathrm{MW}$ power plant. The results illustrate that when pulverize outlet temperature rised form $70^{\circ} \mathrm{C}$ to $94^{\circ} \mathrm{C}$, temperature of gas center 0.4 meter, 0.5 meter and 0.6 meter apart from A2 burner all rised, temperature of gas center 0.4 meter apart from burner rised fast form $538^{\circ} \mathrm{C}$ to $820^{\circ} \mathrm{C}$, unburned carbon in fly dust decreased from $2.4 \%$ to $1.7 \%$, unburned carbon in slag decreased from $3.3 \%$ to $2.3 \%$, average temperature located A burner cross section; $\mathrm{C}$ burner cross section; $E$ burner cross section all rised, and boiler thermal efficiency rised from $92.35 \%$ to $92.94 \%$, net coal consumption decreased approximately $2.02 \mathrm{~g} / \mathrm{kW} \cdot \mathrm{h}$.
\end{abstract}

Keywords: bolier, combustion, economy, ignation, temperature in furnace, pulverizer output temperature.

\section{Introduction}

The $65-70 \%$ of China's energy consumption [1] is coal consumption, and the efficient use of coal resources has a significant impact on national energy conservation and emission reduction work. Currently $60 \%$ of coal consumption is used for thermal power generation and heating, it is the important direction of coal energy conservation how to improve combustion efficiency in boilers. It is of great significance to study the effect of pulverized coal parameter changes on boilers in actual operation of boilers.

Li Wenhua et al [2] used a thermogravimetry-Fourier infrared combined analyzer to improve the feasibility of the coal pulverizer outlet temperature. Shen Yueliang et al [3] studied to improve the effects of HP863 coal pulverizer outlet temperature to pulverizing system and combustor nozzle safety, but did not study the temperature change of the pulverized coal gas flow in the actual power station boiler to the temperature change near the combustor nozzle and the furnace temperature field change.

In this paper, the on-site experiment of a $300 \mathrm{MW}$ unit is carried out to study the effect of the change of the coal pulverizer outlet temperature on the boiler operation, including the temperature change of the pulverized coal gas flow center at the combustor outlet, the furnace temperature field change, the pulverized coal burnout performance and analysis of the boiler economy..

\section{Boiler Equipment System Condition}

A power plant boiler, the SG-1025/17.5-M881 single furnace, control cycle, one intermediate reheat pulverized coal furnace, tangential combustion, solid slagging, open-air structure subcritical parameter drum boiler, is produced by Shanghai Boiler Factory Co., Ltd.,. The boiler is equipped with 5 MPS coal pulverizers, which adopts the medium-speed coal pulverizer direct-blowing pulverizing system, and the five-layer primary air nozzle is arranged, of which the four-layer operation can carry the BMCR. The combustor arrangement is shown in Figure 1. The boiler adopts 
four-corner arrangement and concentric reverse tangent combustion mode. The combustor nozzle structure adopts a pattern in which the primary air outlet is surrounded by a peripheral air and a secondary air nozzle is arranged at intervals. The uppermost combustor has an elevation of $26.2 \mathrm{~m}$, the top is provided with a two-layer over firing air (OFA) nozzle, and a two-layer OFA nozzle (not shown in Fig. 1) is provided at $6700 \mathrm{~mm}$ of the primary air nozzle distance from the upper part of the combustor.

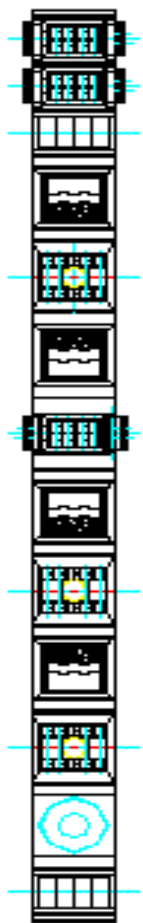

Fig.1 Combustor Arrangement

\section{Experimental Research}

In this experiment, the A, B, C, and D coal pulverizers are operated under the load of $290 \mathrm{MW}$, and the upper part of the combustor is exhausted in four layers. The output of each coal pulverizer is as uniform as possible. The analysis results of the coal samples used are shown in Table 1.

Under the condition that the separator opening degree is $45 \%$ and the air speed in each powder pipeline is $25 \mathrm{~m} / \mathrm{s}$, the effect of the coal pulverizer outlet temperature on the boiler is studied. Before the experiment, each layer opening degree of the powder pipeline is adjusted to change pulverizer outlet temperature by adjusting the pipe shrinkage hole and the dial display value is used during the experiment. To ensure the normal and safe operation of the milling system, four working conditions of $70{ }^{\circ} \mathrm{C}, 78{ }^{\circ} \mathrm{C}, 86^{\circ} \mathrm{C}$, and $94{ }^{\circ} \mathrm{C}$ are selected and temperature in each pipe see Table 2.

Use the air bleed thermocouple to measure the center temperature of the pulverized coal gas flow at a distance of about $0.4 \mathrm{~m}$ from the nozzle, and select the A-layer combustor \#2 angle at the experiment position. Pre-measure the distance during the shutdown and on the furnace platform mark the location of the pumping thermocouple.

Infrared pyrometer is used to measure the temperature inside the furnace at the fire hole. The temperature of each layer is taken as the average value of the four measuring points of the layer. The experiment position is selected from the A layer, $\mathrm{C}$ layer and $\mathrm{E}$ layer platform. At the air preheater A, B inlet, the fly ash is collected by the constant velocity sampling method and averaged; the slag is sampled several times in the outlet of the dry slag removal machine [4]. 
Table 1 Proximate and Ultimate Analysis of Coal Sample

\begin{tabular}{ccccccccccc}
\hline \multicolumn{4}{c}{ Proximate analysis (\%) } & \multicolumn{3}{c}{ Net calorific value $(\mathrm{kJ} / \mathrm{kg})$} & \multicolumn{4}{c}{ Ultimate analysis $(\%)$} \\
\hline Mt & Mad & Aad & Vad & FCad & $\mathrm{Q}_{\text {net.ar }}$ & $\mathrm{C}_{\mathrm{ar}}$ & $\mathrm{H}_{\mathrm{ar}}$ & $\mathrm{N}_{\mathrm{ar}}$ & $\mathrm{S}_{\mathrm{t}, \mathrm{ar}}$ & $\mathrm{O}_{\mathrm{ar}}$ \\
\hline 13.10 & 6.69 & 18.91 & 29.41 & 44.99 & 21923 & 55.71 & 3.67 & 0.91 & 0.49 & 9.26 \\
\hline
\end{tabular}

Table 2 Temperature of Primary Air Mixed Pulverized Coal Particles $\left({ }^{\circ} \mathrm{C}\right)$

\begin{tabular}{ccccccccc}
\hline Pipeline No. & A1 & A2 & A3 & A4 & B1 & B2 & B3 & B4 \\
\hline Work Condition 1 & 71.6 & 69.8 & 67.6 & 69.6 & 72.1 & 70.1 & 71.0 & 70.5 \\
Work Condition 2 & 78.8 & 77.6 & 76.7 & 79.1 & 79.6 & 78.4 & 78.2 & 77.1 \\
Work Condition 3 & 88.5 & 85.5 & 86.6 & 86.6 & 85.2 & 84.9 & 86.6 & 86.9 \\
Work Condition 4 & 94.6 & 94.4 & 93.2 & 95.5 & 95.5 & 93.3 & 93.1 & 92.9 \\
\hline Pipeline No. & C1 & C2 & C3 & C4 & D1 & D2 & D3 & D4 \\
\hline Work Condition 1 & 70.3 & 73.6 & 68.8 & 69.3 & 71.6 & 69.2 & 71.9 & 69.8 \\
Work Condition 2 & 77.2 & 79.3 & 78.9 & 77.4 & 79.7 & 78.5 & 78.7 & 76.8 \\
Work Condition 3 & 87.7 & 85.7 & 86.1 & 85.0 & 87.2 & 86.4 & 86.4 & 86.7 \\
Work Condition 4 & 94.4 & 95.1 & 95.0 & 94.6 & 93.5 & 94.4 & 94.0 & 94.8 \\
\hline
\end{tabular}

\section{Experiment Results and Discussion}

\subsection{Effect of Coal Pulverizer Outlet Temperature on Boiler Combustion}

\subsubsection{Effect of Coal Pulverizer Outlet Temperature to Pulverized Coal Gas Flow Center Temperature}

It can be seen from Fig. 2 that, as the outlet temperature of the coal pulverizer increases, the temperature of the pulverized coal gas flow center at a distance of $0.4 \mathrm{~m}, 0.5 \mathrm{~m}$ and $0.6 \mathrm{~m}$ from the nozzle shows a significant increase. The temperature at $0.4 \mathrm{~m}$ rises from the operating condition one of $538{ }^{\circ} \mathrm{C}$ to $820{ }^{\circ} \mathrm{C}$ in working condition 4 . Generally, the bituminous coal is higher than $700{ }^{\circ} \mathrm{C}$, which means that it is on fire, indicating that, as the outlet temperature increases, the pulverized coal gas flow distance is reduced by more than $0.4 \mathrm{~m}$ and successively decreases. The pulverized coal gas flow temperature is $745^{\circ} \mathrm{C}$, indicating that the ignition distance is less than $0.4 \mathrm{~m}$ at this time. The pulverized coal gas flow temperature at $0.5 \mathrm{~m}$ and $0.6 \mathrm{~m}$ is higher than $700{ }^{\circ} \mathrm{C}$ under four working conditions, and it can be considered that both positions have been significantly ignited. The pulverized coal ignition can be divided into four. Time period [5]: heat flow penetration time, pulverized coal heating time, combustible material mixing time and reaction induction time, initial temperature increase leads to faster internal heat transfer to pulverized coal particles, $\mathrm{CO}$ is mainly generated through the breakage of carbonyl, ether bridge bond and other oxygen-containing groups [6]. The increase of pulverized coal temperature is beneficial to the breaking of chemical bonds, the precipitation of $\mathrm{CO}$ accelerates the concentration increase. The temperature increases, the diffusion of $\mathrm{O}_{2}$ molecules accelerates, the ignition time advances, the heat is released earlier and the temperature is elevated at this position.

\subsubsection{Effect of Carbon Content in Ash}

It can be seen from Fig. 3 that, as the outlet temperature of the coal pulverizer increases, the ignition time is advanced, and the content of combustibles in the fly ash and slag is decreasing. The carbon content of fly ash and slag in working condition 1 is $2.4 \%, 3.3$. \%, respectively, indicating 
that the pulverized coal incomplete combustion and loss is too high at this time. As the temperature of the combustor nozzle air rises, the lower part of the furnace is ignited and the combustion is strengthened. The flame center is moved down, the combustor area receives more heat, further promoting fuel efficiency combustion and combustion efficiency is improved.

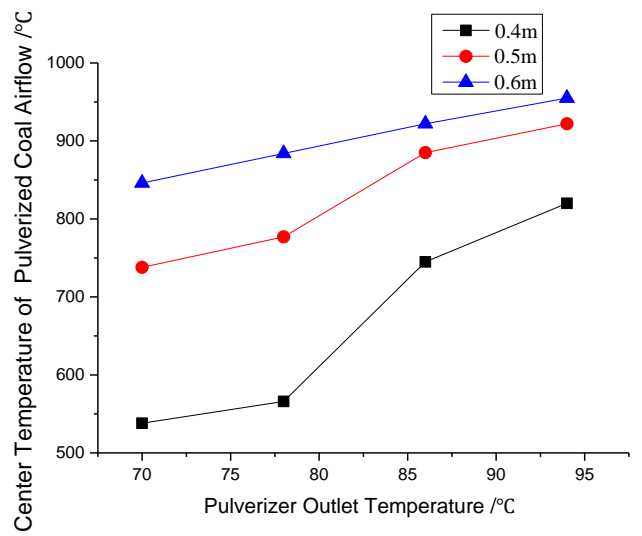

Fig. 2 Temperature variation in the center of pulverized coal airflow

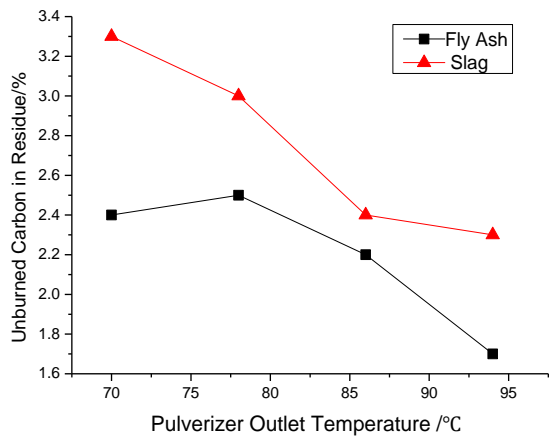

Fig. 3 Unburned Carbon Variation in Fly Ash and Slag

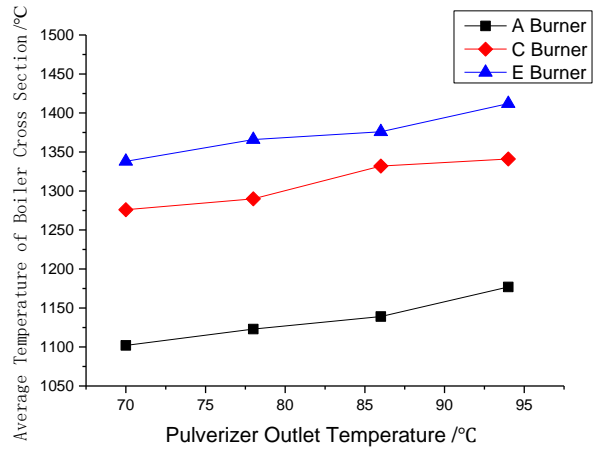

Fig. 4 Average Temperature Variation of Boiler Cross Section

\subsubsection{Effect of Temperature Field in the Furnace}

It can be seen from Fig. 4 that, as the outlet temperature of the coal pulverizer increases, the average temperature of the section of the furnace where the A-layer combustor, the C-layer combustor and the E-layer combustor increases significantly.

The high-temperature flue gas heats the pulverized coal particles through convection and radiation. At high temperature, $\mathrm{O}_{2}$ accelerates the diffusion along the pores of the pulverized coal. The pulverized coal with smaller particle size directly undergoes multi-phase ignition reaction [7], the volatile heat of large-sized pulverized coal thermal decomposition the small molecules that produce $\mathrm{CO}$ and other combustibles with the $\mathrm{O}_{2}$ that diffuse through the pores are ignited [8], and the heat is released to promote more pulverized coal. The analysis shows that, as the temperature of the inlet medium increases, the pulverized coal releases heat in advance. The temperature rise near the nozzle of the combustor and is conducive to the combustion and burning of the pulverized coal, thereby the carbon content of the ash is reduced. The pulverized coal releases heat at this position, the average temperature of the section A combustor is increased, and the average temperature of the section of the $\mathrm{C}$ layer combustor is also increased. Because the unburned particles and combustible gases carried in the airflow below the C-layer combustor continue to burn here, release a certain amount of heat. The average temperature of the $\mathrm{C}$ layer is higher than that of the A layer and the E-layer combustor is not put into operation, but The increase in the combustible composition and heat carried by the 
lower airflow causes the average temperature of the E-layer section to rise. The E layer is closer to the center of the flame, and the average temperature is higher than that of the $\mathrm{C}$ layer.

\subsection{Impact of Boiler Economy}

The boiler economy is mainly reflected in the boiler thermal efficiency. According to the GB10184-1988 Power Plant Boiler Performance Experiment Regulations, the thermal efficiency calculation is carried out for the four working conditions. The results are shown in Table 3 . It can be concluded from Table 3 that, as the coal pulverizer outlet temperature rises, the measured smoke exhaust temperature is decreasing. The corrected smoke exhaust temperature is reduced from 149.5 ${ }^{\circ} \mathrm{C}$ to $141.5{ }^{\circ} \mathrm{C}$. The corrected smoke exhaust heat loss is reduced from $6.43 \%$ to $6.05 \%$, and the carbon content of the ash is reduced. The heat loss of solid incomplete combustion decreased from $0.66 \%$ to $0.46 \%$. The corrected boiler thermal efficiency increased from $92.35 \%$ to $92.94 \%$. Assuming factory electricity consumption is $5 \%$, pipeline efficiency is $99 \%$, and unit heat consumption is $8100 \mathrm{~kJ} /(\mathrm{kWh})$. The coal consumption for power supply decreases from 318.21 $\mathrm{g} / \mathrm{kWh}$ to $316.19 \mathrm{~g} / \mathrm{kWh}$. If the annual utilization period of power generation is $5000 \mathrm{~h}$, the single unit can save $3030 \mathrm{t}$ standard coal with obvious economic benefits.

Table 3. Calculation Result of Thermal Efficiency

\begin{tabular}{|c|c|c|c|c|c|}
\hline Project & Unit & Condition 1 & Condition 2 & Condition 3 & Condition 4 \\
\hline $\mathrm{O}_{2}$ content of smoke exhaust & $\%$ & 5.18 & 5.32 & 5.14 & 5.24 \\
\hline CO content of smoke exhaust & ppm & 124 & 146 & 88 & 96 \\
\hline Measured smoke exhaust temperature & ${ }^{\circ} \mathrm{C}$ & 148.8 & 145.2 & 143.8 & 142.5 \\
\hline System inlet air temperature & ${ }^{\circ} \mathrm{C}$ & 18.8 & 20.2 & 22.2 & 21.5 \\
\hline Air relative humidity & $\%$ & 28.8 & 12.4 & 11.2 & 17.8 \\
\hline Atmospheric pressure & $\mathrm{Pa}$ & 101880 & 101720 & 101700 & 101760 \\
\hline Corrected smoke exhaust temperature & ${ }^{\circ} \mathrm{C}$ & 149.5 & 145.1 & 142.4 & 141.5 \\
\hline Corrected smoke exhaust heat loss & $\%$ & 6.43 & 6.23 & 6.04 & 6.05 \\
\hline $\begin{array}{l}\text { Corrected flammable gas incomplete } \\
\text { combustion heat loss }\end{array}$ & $\%$ & 0.05 & 0.06 & 0.04 & 0.04 \\
\hline $\begin{array}{l}\text { Corrected solid incomplete combustion } \\
\text { heat loss }\end{array}$ & $\%$ & 0.66 & 0.68 & 0.59 & 0.46 \\
\hline Corrected heat loss & $\%$ & 0.43 & 0.43 & 0.43 & 0.43 \\
\hline Corrected ash physical heat loss & $\%$ & 0.08 & 0.07 & 0.07 & 0.07 \\
\hline Corrected boiler thermal efficiency & $\%$ & 92.35 & 92.52 & 92.83 & 92.94 \\
\hline
\end{tabular}

\section{Conclusion}

With the increase of the outlet temperature of the coal pulverizer, the pulverized coal fire is strengthened and the temperature at the same position of the pulverized coal flow at the outlet of the combustor is increased. The heat released from the lower part of the furnace is increased and the average temperature of furnace section of the combustor layer of the A layer, the $\mathrm{C}$ layer and the $\mathrm{E}$ layer is increased. The pulverized coal burnout effect is good and the ash content of carbon ash is reduced.

The export temperature of the coal pulverizer is increased from $70{ }^{\circ} \mathrm{C}$ to $94{ }^{\circ} \mathrm{C}$. The corrected boiler thermal efficiency is increased from $92.35 \%$ to $92.94 \%$. The coal consumption of the power 
supply is reduced. The standard coal can be saved $3030 \mathrm{t}$ in the whole year and the economic benefits are remarkable.

\section{References}

[1]. National Bureau of Statistics of China. 2014 Statistical Yearbook of China [M].China Statistics Press, 2014.

[2]. Li Wenhua, Yang Jianguo, Cui Fuxing, et al. Influence of Improving Medium-speed Pulverizer Outlet Temperature on the Operation of Boiler[J].Electric Power, 2010,43(10):27-30.

[3]. Shen Yueliang, Chen Mouwan, Liu Yaming, et al.Effect of Enhancing Outlet Temperature of HP983 Pulverizer on Boiler Operation[J].Thermal Power Generation, 2013,42(4):9-13.

[4]. GB 10184-1988, Performance Test Code for Utility Boiler[S].

[5]. Kalyan Annamalai, Wliilam Ryan. Experimental Studies on the Group Ignation of a Cloud of Coal Particles Volume II Pyrolysis and Ignation Modeling [J].Distribution Category UC-103, 1991, 12(2), 104.

[6]. Sada E, Kumazawa H, Kudsy M.Pyrolysis of lignins in molten salt media [J]. Ind Eng Chem res, 1992,$31 ; 612-636$.

[7]. Cen Kefa, Yao Qiang, Luo Zhongyang, et al. Advanced Combustion [M].Zhejiang University Press, 2002, 303-303.

[8]. V.S. Gururajan.Mechanisms for the ignition of pulverized coal particles. Combustion and Flame, 1990, 81(2), 119-132. 